\title{
Food insecurity, social networks and symptoms of depression among men and women in rural Uganda: a cross-sectional, population-based study
}

\author{
Jessica M Perkins ${ }^{1, *}$, Viola N Nyakato ${ }^{2}$, Bernard Kakuhikire ${ }^{2}$, Alexander C Tsai ${ }^{1,2,3}$, \\ SV Subramanian ${ }^{3,4}$, David R Bangsberg ${ }^{2,5}$ and Nicholas A Christakis ${ }^{6}$ \\ ${ }^{1}$ Chester M. Pierce, MD Division of Global Psychiatry, Massachusetts General Hospital, 125 Nashua Street 7th floor, \\ Suite 722, Boston, MA 0211 4, USA: ${ }^{2}$ Mbarara University of Science and Technology, Mbarara, Uganda: ${ }^{3}$ Harvard \\ Center for Population and Development Studies, Cambridge, MA, USA: ${ }^{4}$ Department of Social and Behavioral \\ Sciences, Harvard T.H. Chan School of Public Health, Boston, MA, USA: ${ }^{5}$ Oregon Health \& Science University- \\ Portland State University School of Public Health, Portland, OR, USA: ${ }^{6}$ Yale Institute for Network Science, Yale \\ University, New Haven, CT, USA
}

Submitted 11 February 2017: Final revision received 27 June 2017: Accepted 12 July 2017: First published online 9 0ctober 2017

\begin{abstract}
Objective: To assess the association between food insecurity and depression symptom severity stratified by sex, and test for evidence of effect modification by social network characteristics.

Design: A population-based cross-sectional study. The nine-item Household Food Insecurity Access Scale captured food insecurity. Five name generator questions elicited network ties. A sixteen-item version of the Hopkins Symptom Checklist for Depression captured depression symptom severity. Linear regression was used to estimate the association between food insecurity and depression symptom severity while adjusting for potential confounders and to test for potential network moderators.

Setting: In-home survey interviews in south-western Uganda.

Subjects: All adult residents across eight rural villages; $96 \%$ response rate ( $n$ 1669). Results: Severe food insecurity was associated with greater depression symptom severity $(b=0.4,95 \%$ CI $0.3,0 \cdot 5, P<0.001$ for women; $b=0.3,95 \%$ CI $0 \cdot 2,0 \cdot 4$, $P<0.001$ for men). There was no evidence of effect modification by social network factors for women. However, for men who are highly embedded within in their village social network, and (separately) for men who have few poor contacts in their personal network, the relationship between severe food insecurity and depression symptoms was stronger than for men on the periphery of their village social network, and for men with many poor personal network contacts, respectively.

Conclusions: In this population-based study from rural Uganda, food insecurity was associated with mental health for both men and women. Future research is needed on networks and food insecurity-related shame in relation to depression symptoms among food-insecure men.

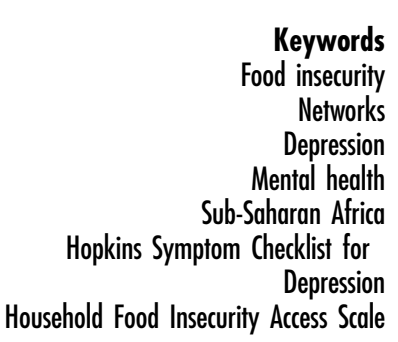

Keywords

Networks

Depression

Mental health

Checklist for

Depression

Household Food Insecurity Access Scale
\end{abstract}

From 1990 to 2014, the number and proportion of undernourished people increased in nine countries in subSaharan Africa ${ }^{(1)}$. This increase occurred despite a global focus over the last two decades on the first Millennium Development Goal calling for reductions in poverty and hunger. In 2015, the Sustainable Development Goals were created where Goal 2 was to 'end hunger, achieve food security and improve nutrition, and promote sustainable agriculture' by $2030^{(2)}$. Food insecurity is 'defined by the lack of secure access to sufficient amounts of safe and nutritious food for normal growth and development and an active and healthy life ${ }^{,(3)}$. Food insecurity experienced as an adult can lead to serious physical health consequences $^{(4-9)}$ and has been shown to correlate with psychological distress in some populations ${ }^{(5,9-17)}$. In subSaharan Africa, past research has linked food insecurity to psychological distress among vulnerable populations including HIV-positive patients, pregnant and postpartum women, refugees and immigrants, and other samples of note ${ }^{(18-25)}$. In addition, a longitudinal study in Zambia 
found that food insecurity affected mental health among a group of adults in eighty-one households across sixteen villages, and did so even more during the dry $\operatorname{season}^{(26)}$

\section{Conceptual framework}

First, the relationship between food insecurity and mental health may differ between men and women across different societies depending on local gender norms. In cultures where women traditionally are responsible for food preparation such as in sub-Saharan Africa ${ }^{(27)}$, the relationship between food insecurity and depression may be stronger for women, which previous research suggests $^{(10,21,28,29)}$. However, men might still feel responsible for making sure that enough money is available to purchase (or grow) sufficient food. Thus, it is important to assess the relationship between food insecurity and mental health separately for men and women to improve the design of interventions. In addition, the extent to which an independent and direct association exists between food insecurity and mental health after adjusting for socio-economic status should be assessed for both men and women as past work has found economic status to be a predictor of food insecurity ${ }^{(30-33)}$ as well as a predictor of mental health ${ }^{(34,35)}$.

Second, the social support and stress-buffering literature ${ }^{(36-38)}$ would suggest that social support may moderate the relationship between food insecurity and psychological distress. Although a few studies have found that perceptions of social support buffer the association between food insecurity and psychological distress ${ }^{(21,23,29,39,40)}$, at least one study has shown no evidence of effect modification ${ }^{(41)}$. Moreover, no studies have examined how the actual arrangement and composition of social ties around an individual (i.e. the social network) may inhibit (or enhance) the food security-depression relationship. On the one hand, social networks represent the structure through which support may flow and which may also themselves generate support, particularly in places lacking formal sources of assistance ${ }^{(42,43)}$. People experiencing food insecurity but who have many social ties, who are highly embedded within their community network or who have a tightly connected personal network may feel supported or be able to access resources if needed and exhibit fewer depression symptoms. In contrast, people experiencing substantial food insecurity who have few social ties, who are on the social periphery of a community network or who have a loosely connected personal network may feel less instrumentally or emotionally supported, experience more stress and exhibit more depression symptoms. Similarly, for people with personal contacts who are mostly poor, experiencing food insecurity may lead to more depression symptoms due to perceiving that their personal network would likely not be able to provide material help if asked, as compared with people who are also experiencing food insecurity but who have fewer poor contacts.
On the other hand, social network factors may also serve to heighten negative feelings associated with food insecurity such as shame and embarrassment ${ }^{(13,44,45)}$. For example, a food-insecure individual with many personal ties or who is highly centralized in a social network may begin to feel acute stress as gossip about his or her situation could spread to more people. Similarly, feelings of shame might be greater among food-insecure people with a personal network whom they assume to be less understanding of food insecurity, such as networks with a lower composition of visibly poor people. In addition, food-insecure individuals with a network comprising a small proportion of food-insecure contacts may internalize a negative sense of perceived 'otherness' as compared with food-insecure people with proportionally more foodinsecure contacts. (This latter form of modification may only happen, however, if contacts do not attempt to hide their food insecurity status.)

Thus, social network work factors may modify the food insecurity-depression relationship; for example, by strengthening or weakening perceptions of support or actual support, or enhancing or reducing feelings of shame. These perceptions and feelings may, in turn, directly increase or reduce symptoms of depression. Alternatively, they may indirectly do so; for example, by reducing the likelihood that food-insecure individuals will request support from their networks. No prior research has assessed whether social network characteristics moderate the association between food insecurity and mental health within the general population. Moreover, sex differences could exist in how social network factors act as modifiers given sex-based effect modification results from past studies when using measures of perceived social support $^{(46-48)}$. For example, food-insecure men might feel embarrassed by their situation among wealthy friends and thus develop further symptoms of depression. In contrast, food-insecure women might not if they are more used to the situation or it is more socially acceptable to talk about being very food insecure among their friends regardless of wealth status.

\section{The current study}

To address these gaps in the literature, we undertook a cross-sectional, population-based study in rural Uganda. In this context, the local economy is largely based on subsistence agriculture, and food and water insecurity are common $^{(48,49)}$. Transportation is a difficult economic barrier and reinforces geographic isolation ${ }^{(50,51)}$. Few households have access to electricity, unequal gender norms are strong ${ }^{(52)}$ and fertility rates are high ${ }^{(53)}$. Healthcare infrastructure is limited and agricultural assistance and training are rare ${ }^{(53)}$.

Our study had two aims. First, we assessed the direct relationship between food insecurity and depression symptoms severity among adult men and women, separately, in rural Uganda after adjusting for several potential 
confounders such as socio-economic status. Second, we assessed whether social network position, structure and composition (e.g. number of ties, social location within a community network, the structural arrangement of personal ties around an individual, the wealth composition and food security composition of an individual's immediate contacts) moderated the association between food insecurity and depression for men and women separately.

\section{Methods}

\section{Study population}

The study targeted all adults (aged 18 years or older) whose main household was located within one parish containing eight villages in rural south-western Uganda, a very low-resource setting about $260 \mathrm{~km}$ south-west of the capital city, Kampala. The study team was comprised of several well-trained research assistants from the surrounding district who spoke the local language. They used a census enumeration to continuously search for all 1939 potential participants across the 716 households listed as belonging to the parish. By the end of the data collection period, the research assistants had found and interviewed 1669 eligible people. Among the remaining 270 people, sixteen refused, sixty-two could not be contacted (because the person was away from the parish during every attempted contact), 166 became ineligible as their primary residence had shifted outside the parish, eleven were consistently too incapacitated/sick to participate and fifteen had died. Thus, after excluding the people who were ineligible, incapacitated or who had died, the response rate was $1669 / 1747=96 \%$. There was little variation in response rate across villages.

\section{Procedures}

Interview materials were translated, back-translated and pilot-tested in an iterative process to ensure accuracy, consistent word choice and linguistic equivalence. Between October 2011 and August 2012, trained local research assistants conducted one-on-one structured interviews (lasting about an hour) with eligible participants, typically at a participant's place of residence. All participants provided written informed consent, either with a signature or, if there were cultural literacy reasons why a signature was not appropriate, a thumbprint.

\section{Depression symptom severity}

We used a slightly modified version of the fifteen-item Hopkins Symptom Checklist for Depression (HSCL-D) ${ }^{(54)}$, by including a sixteenth item ('Feeling like I don't care about my health') that prior studies had included for use in the Ugandan context ${ }^{(21,55-57)}$. Participants were asked how often in the last $7 \mathrm{~d}$ they had experienced each of the sixteen symptoms using a 4-point scale representing 'not at all' to 'extremely often' (coded 0 to 3). Cronbach's $\alpha$ was $0 \cdot 84$. The total depression symptom severity score was the mean of all items (no missing permitted), with higher scores representing more symptoms. Some $4.6 \%$ of participants had a missing depression symptom severity score. For use in describing the population and in a sensitivity analysis, participants were classified as symptomatic of having 'probable depression' if they had a score of 1.75 or greater, which is a commonly used threshold ${ }^{(21,54,58)}$.

\section{Food insecurity}

Individual perception of household food insecurity was measured using the nine-item Household Food Insecurity Access Scale (HFIAS or simply food insecurity) ${ }^{(59)}$, which a previous study had adapted for use in Uganda ${ }^{(21)}$. Participants were asked how often in the past $30 \mathrm{~d}$ they had experienced different food insecurity-related situations using a 4-point scale representing 'never' to 'often' (coded 0 to 3). Cronbach's $\alpha$ was $0 \cdot 85$. A summary score was created (no missing was permitted). Higher scores represented greater food insecurity (maximum $=27$ ). Some $1.9 \%$ of participants had a missing food insecurity score. Using a validated scoring algorithm, the scores on the raw scale were used to assign respondents to categories of food insecurity severity: 'none' (food secure), 'mildly food insecure', 'moderately food insecure' and 'severely food insecure, ${ }^{,(59)}$.

\section{Social network position, structure and composition}

We first employed 'name generator' questions to elicit study participants' social ties ${ }^{(60)}$. The canonical example of a name generator frequently used in US-based surveys is the question embedded in the US General Social Survey: 'From time to time, most people discuss important matters with other people. Looking back over the last six months who are the people with whom you discussed matters important to you? ${ }^{(60)}$. Consistent with the literature ${ }^{(61)}$, however, we adapted five name generator questions for the local context. All participants were asked to name up to six adult parish residents in response to each of the name generator questions. The questions inquired about with whom or to whom, in the past 12 months, the participant (i) spent free time, (ii) discussed financial topics, (iii) discussed health matters, (iv) went to for emotional support and (v) shared, exchanged, received or gave food, in that order. Names could be repeated for each network type. Previous research has shown that by utilizing information from across multiple name generators, estimates of network characteristics are more accurate ${ }^{(62)}$. Thus, we collapsed information across the five network types and created several variables to describe an individual's position within the community social network, the structure of his or her personal network, and the composition of his or her personal network. 
We started by calculating: (i) the number of people whom an individual nominated not including duplicates (i.e. 'out degree'); (ii) the number of people whom an individual nominated who also nominated the individual (i.e. 'reciprocal degree'); and (iii) the total number of out-going plus in-coming nominations not including duplicates (i.e. 'total degree'), which is also referred to as personal network size. We then calculated the density of a participant's personal network by dividing the total number of ties among a participant's contacts (ignoring nomination direction) by the total number of ties that could have possibly existed among a participant's contacts. In addition, we calculated a variable representing a participant's embeddedness within his or her village social network. That is, we calculated how close a participant was to all other people within his or her village network by taking the inverse of the sum of the shortest distance across same-village ties between a participant and every other person in his or her village (i.e. 'closeness'). We then created equally distributed quintile categories representing an individual's closeness, which could range from very peripheral (lowest quintile) to very central (highest quintile). These variables are typically included in social network analysis and represent traditional measures of an individual's centrality in a network and network structure ${ }^{(63,64)}$. Finally, to measure personal network composition, we calculated the percentage of a participant's personal network that was poor (see next paragraph for wealth definition) and the percentage of the participant's personal network that reported moderate or severe food insecurity. We then categorized these composition percentages of 0 to 100 into quintiles.

\section{Other explanatory variables}

Participants also reported age, tribe, marital status, educational attainment, alcohol consumption frequency and HIV status. Age was categorized as: (i) less than 30 years old; (ii) 40-49 years; (iii) 50-59 years; (iv) 60-69 years; and (v) 70 years or older. Participants were either part of the Banyankore tribe or another tribe. Marital status was split as married or other. Education was categorized as primary schooling or less $v$. secondary schooling or more; and alcohol consumption as two or more times per week $v$. less often. Participants reported being HIV positive or negative/ unknown. In addition, two household-level measures were included: (i) whether there had been a death in the household in the past 12 months; and (ii) household wealth. The latter was measured via a household asset index, by conducting a principal components analysis on twenty-six separate variables representing household assets and housing characteristics. We retained the first principal component to define the asset index ${ }^{(65)}$ and categorized anyone in a household in the first two quintiles of the asset index as 'poor'. We also created a variable indicating whether the interview was conducted in the rainy season, as prior research has shown food insecurity to be greater during the dry season in Uganda ${ }^{(66,67)}$ and across subSaharan Africa more generally ${ }^{(68)}$. In addition, dummy variables were created to represent village of residence. These explanatory variables were utilized in our analyses to adjust for potential confounding as prior research has linked them to food security and mental health outcomes in similar populations ${ }^{(10,21,26,69-71)}$.

\section{Statistical analyses}

After removing participants with missing responses on any of the study variables, the final analytic population consisted of 1499 people (677 men and 822 women). The distribution of men and women across sociodemographic characteristics was calculated. To test for simple differences between men and women in terms of depression symptom severity, having symptoms indicative of 'probable depression' and, separately, being food insecure, we used Pearson's $\chi^{2}$ test for categorical variables and the nonparametric equality-of-medians test for the continuous variable. To assess the continuous association between food insecurity and depression symptom severity among adults in rural Uganda, we first fitted a linear regression model stratified by sex with random effects at the household level and a series of fixed effects for explanatory variables (Model 1). Our main independent variable was food insecurity although we also adjusted for age, tribe, marital status, HIV status, alcohol consumption, education, household wealth, having had a death in the household in the past year, village and season in which the interview was conducted. We also fitted a fully adjusted, sex-stratified logistic regression model (where having 'probable depression' was the outcome) to check whether those estimates were similar to estimates produced by the linear model. Finally, to test for effect modification by sex, we fitted a supplemental linear regression model where we pooled data for men and women and included an interaction effect between food insecurity and sex.

To address our second study aim and look for evidence of effect modification by social network characteristics, we ran a series of sex-stratified analyses using a second model that included the main effect for a network variable and the associated interaction effect between that network variable and food insecurity in addition to the variables in Model 1. (When Model 2 included the personal network structure variable or a network composition variable, we also adjusted for the main effect of total personal network size.) All statistical tests were two-sided and significance was considered at $P<0.05$ for all tests.

\section{Results}

Overall, the mean level of depression symptom severity was greater among women than among men (1.52 v. 1.28, $P<0.001)$, as was the prevalence of symptoms that were indicative of having 'probable depression' (women: $n$ 205, 
$25 \%$; men: $n$ 63, 9\%; $P<0 \cdot 001$; Table 1$)$. Likewise, $76 \%$ of women and $67 \%$ of men reported any degree of food insecurity $(P<0.001)$, with $24 \%$ of women and $16 \%$ of men reporting severe food insecurity $(P<0.001)$. While the mean number of nominated contacts was a little over five contacts for both men and women, men had a mean total personal network size of $9 \cdot 1$ (SD 6.0) contacts and women had a mean total personal network size of 8.6 (sD 4.7) contacts. Men's mean closeness score was 0.23 and women's mean closeness score was $0 \cdot 24$, both with SD of 0.02 . About one-third of an individual's personal network contacts (33\% for men and 30\% for women) were categorized as poor, on average (with SD of 24 and 23\%, respectively). Finally, $48 \%$ of men's personal network contacts and $56 \%$ of women's personal network contacts, on average, reported moderate or severe food insecurity (with SD of $23 \%$ for both men and women).

According to sex-stratified regression analyses, the results from Model 1 showed that severe food insecurity among women was associated with a 0.41-point increase in depression symptom severity (95\% CI $0.31,0.50)$

Table 1 Descriptive characteristics of men and women aged 18 years or older across eight villages in rural south-western Uganda

\begin{tabular}{|c|c|c|c|c|}
\hline & \multicolumn{2}{|c|}{ Women } & \multicolumn{2}{|c|}{ Men } \\
\hline & $n$ & $\%$ & $n$ & $\%$ \\
\hline Total & 822 & 55 & 677 & 45 \\
\hline \multicolumn{5}{|c|}{ Having symptoms indicative of 'probable depression' } \\
\hline No & 617 & 75 & 614 & 91 \\
\hline Yes & 205 & 25 & 63 & 9 \\
\hline \multicolumn{5}{|l|}{ Food insecurity } \\
\hline None & 194 & 24 & 218 & 32 \\
\hline Mild & 141 & 17 & 138 & 20 \\
\hline Moderate & 291 & 35 & 213 & 31 \\
\hline Severe & 196 & 24 & 108 & 16 \\
\hline \multicolumn{5}{|l|}{ Age } \\
\hline$<30$ years & 356 & 43 & 284 & 42 \\
\hline $30-39$ years & 159 & 19 & 145 & 21 \\
\hline 40-49 years & 124 & 15 & 118 & 17 \\
\hline 50-59 years & 66 & 8 & 61 & 9 \\
\hline $60-69$ years & 52 & 6 & 33 & 5 \\
\hline$\geq 70$ years & 65 & 8 & 36 & 5 \\
\hline \multicolumn{5}{|l|}{ Tribe } \\
\hline Banyankore tribe & 733 & 89 & 641 & 95 \\
\hline Other tribe & 89 & 11 & 36 & 5 \\
\hline \multicolumn{5}{|l|}{ Married } \\
\hline No & 352 & 43 & 261 & 39 \\
\hline Yes & 470 & 57 & 416 & 61 \\
\hline \multicolumn{5}{|l|}{ HIV positive } \\
\hline No/unknown & 755 & 92 & 641 & 95 \\
\hline Yes & 67 & 8 & 36 & 5 \\
\hline \multicolumn{5}{|l|}{ Drinks alcohol $\geq 2$ times/week } \\
\hline No & 807 & 98 & 520 & 77 \\
\hline Yes & 15 & 2 & 157 & 23 \\
\hline \multicolumn{5}{|l|}{ Education } \\
\hline Secondary school or more & 221 & 27 & 253 & 37 \\
\hline Primary school or less & 601 & 73 & 424 & 63 \\
\hline \multicolumn{5}{|l|}{ Poor } \\
\hline No & 526 & 64 & 454 & 67 \\
\hline Yes & 296 & 36 & 222 & 33 \\
\hline \multicolumn{5}{|l|}{ Household death in past year } \\
\hline No & 757 & 92 & 624 & 92 \\
\hline Yes & 65 & 8 & 53 & 8 \\
\hline
\end{tabular}

compared with women reporting no food insecurity, adjusting for several other factors (Table 2). Separately, severe food insecurity among men was associated with a 0.31-point increase in depression symptom severity ( $95 \%$ CI $0 \cdot 24,0.39)$ compared with men reporting no food insecurity. Similarly, moderate food insecurity was associated with greater depression symptom severity for both men and women although the estimate was three to four times less than the estimate for severe food insecurity. In relative terms, the magnitude of the association of severe (and moderate) food insecurity with depression symptom severity was greater than that of all the other sociodemographic variables. The logistic regression analyses using the binary outcome of having symptoms indicative of 'probable depression' demonstrated similar results; women and men reporting severe food insecurity were about 5.2 times (95\% CI 2.9, 9.4) and 4.6 times (95\% CI 1.9 , 11.0) more likely, respectively, to have symptoms indicative of 'probable depression' than adults reporting no food insecurity. In addition, women who experienced moderate food insecurity were 2.0 times more likely to have symptoms indicative of 'probable depression' (95\% CI $1 \cdot 1,3 \cdot 5)$. The estimate for the parallel group of men was similar, but not significant.

Supplemental regression results indicated a statistically significant interaction effect between sex and severe food insecurity ( $b=0 \cdot 14,95 \% \mathrm{CI} 0 \cdot 02,0 \cdot 25, P=0.03$ ); women with severe food insecurity were predicted to have $0 \cdot 28$ point increase in depression symptom severity compared with men with severe food insecurity. There were no differences in depression symptom severity between women and men at lower levels of food insecurity.

Regression analyses testing for evidence of moderator effects found no statistically significant interactions between any of the social network variables and food insecurity for women. (Moreover, there were no main effect associations of social network characteristics with depression symptom severity for women.) For men, however, regression results from Model 2 indicated a statistically significant interaction between food insecurity and closeness quintile (i.e. an individual's social location within the village network; $F=3.41, P=0.019$; Table 3 ). Thus, when stratifying Model 2 by categories of closeness, among men in the most peripheral category of closeness, there was no statistically significant association of any level of food insecurity with depression symptom severity. In contrast, among men in the most central category of closeness, severe food insecurity had a statistically significant association with depression symptom severity ( $b=0.53,95 \%$ CI $0.28,0.77, P=0.004)$, which was more than 1.5 times larger in magnitude than the overall estimate of the association between food insecurity and depression symptom severity for men. Similarly, among men with the greatest social closeness in their village network, moderate food insecurity also had a statistically significant association with depression symptom severity 
Table 2 Multilevel linear regression estimates for food insecurity and descriptive characteristics predicting depression symptom severity among men and women aged 18 years or older in eight villages in rural south-western Uganda

\begin{tabular}{|c|c|c|c|c|}
\hline & \multicolumn{2}{|c|}{ Model 1 - Women } & \multicolumn{2}{|c|}{ Model 1 - Men } \\
\hline & $b$ & $95 \% \mathrm{Cl}$ & $b$ & $95 \% \mathrm{Cl}$ \\
\hline Intercept & $1 \cdot 28^{\star \star \star}$ & $1.12,1.44$ & $1.03^{\star \star \star}$ & $0.90,1.17$ \\
\hline No food insecurity (reference) & - & - & - & - \\
\hline Mild food insecurity & 0.03 & $-0.07,0.13$ & 0.004 & $-0.06,0.07$ \\
\hline Moderate food insecurity & $0 \cdot 12^{*}$ & $0.03,0.20$ & $0.08^{* *}$ & $0.02,0.15$ \\
\hline Severe food insecurity & $0.41^{\star \star \star}$ & $0.31,0.50$ & $0.31^{* \star \star}$ & $0.24,0.39$ \\
\hline Age (10-year categories) & $0.05^{\star \star \star}$ & $0.03,0.07$ & $0.05^{\star \star \star}$ & $0.03,0.06$ \\
\hline Banyankore tribe ( $v$. other) & $-0.11^{*}$ & $-0.21,-0.01$ & 0.01 & $-0.09,0.12$ \\
\hline Married ( $v$. not) & 0.005 & $-0.06,0.07$ & -0.02 & $-0.07,0.03$ \\
\hline HIV positive ( $v$. not/unknown) & $0.13^{*}$ & $0.02,0.25$ & $0.15^{\star \star}$ & $0.04,0.26$ \\
\hline Drinks alcohol $\geq 2$ times/week ( $v$. less often) & -0.07 & $-0.30,0.16$ & -0.01 & $-0.07,0.05$ \\
\hline Primary school or less ( $v$. secondary school or more) & $0.10^{*}$ & $0.02,0.18$ & 0.03 & $-0.01,0.08$ \\
\hline Household asset index & -0.001 & $-0.02,0.01$ & 0.0004 & $-0.01,0.01$ \\
\hline Death in household in past year ( $v$. none) & $0.21^{\star *}$ & $0.09,0.33$ & 0.02 & $-0.07,0.11$ \\
\hline
\end{tabular}

Estimates were obtained using a two-level, random-intercepts linear regression model which accounted for clustering at the household level and included dummy variables for rainy season and villages.

${ }^{\star} P<0.05,{ }^{\star \star} P<0.01,{ }^{\star \star *} P<0.001$.

Table 3 Multilevel linear regression estimates of interaction effects between food insecurity and two social network characteristics, separately, in predicting depression symptom severity among men aged 18 years or older in eight villages in rural south-western Uganda

\begin{tabular}{|c|c|c|c|c|}
\hline & \multicolumn{2}{|c|}{$\begin{array}{c}\text { Model } 2 \text { - Men; including } \\
\text { personal social } \\
\text { 'closeness' in the village } \\
\text { network }\end{array}$} & \multicolumn{2}{|c|}{$\begin{array}{c}\text { Model } 2 \text { - Men; including } \\
\text { 'percentage of personal } \\
\text { network contacts who are } \\
\text { poor' }\end{array}$} \\
\hline & $b$ & $95 \% \mathrm{Cl}$ & $b$ & $95 \% \mathrm{Cl}$ \\
\hline \multicolumn{5}{|l|}{ Main effects } \\
\hline Intercept & $1 \cdot 16^{\star \star \star}$ & $1 \cdot 05,1 \cdot 26$ & $1.04^{\star \star \star}$ & $0.86,1.21$ \\
\hline No food insecurity (reference) & - & - & - & - \\
\hline Mild food insecurity & -0.06 & $-0.19,0.06$ & 0.04 & $-0.11,0.20$ \\
\hline Moderate food insecurity & -0.03 & $-0.14,0.08$ & 0.05 & $-0.08,0.19$ \\
\hline Severe food insecurity & $0 \cdot 16^{*}$ & $0.08,0.33$ & $0.49^{\star \star}$ & $0.32,0.65$ \\
\hline Closeness centrality (continuous quintiles) & $-0.04^{\star *}$ & $-0.07,-0.01$ & - & - \\
\hline Percentage of network who are poor (based on quintiles representing 0 to $100 \%$ ) & - & - & 0.01 & $-0.04,0.05$ \\
\hline \multicolumn{5}{|l|}{ Interaction effects } \\
\hline Closeness centrality $\times$ No food insecurity & - & - & - & - \\
\hline Closeness centrality $\times$ Mild food insecurity & 0.03 & $-0.01,0.08$ & - & - \\
\hline Closeness centrality $\times$ Moderate food insecurity & $0.06^{\star *}$ & $0.01,0.10$ & - & - \\
\hline Closeness centrality $\times$ Severe food insecurity & $0.07^{\star \star}$ & $0.02,0.13$ & - & - \\
\hline Percentage of contacts who are poor $\times$ No food insecurity & - & - & - & - \\
\hline Percentage of contacts who are poor $\times$ Mild food insecurity & - & - & -0.02 & $-0.09,0.05$ \\
\hline Percentage of contacts who are poor $\times$ Moderate food insecurity & - & - & 0.01 & $-0.05,0.07$ \\
\hline Percentage of contacts who are poor $\times$ Severe food insecurity & - & - & $-0.07^{*}$ & $-0.15,-0.01$ \\
\hline
\end{tabular}

Estimates were obtained using a two-level, random-intercepts linear regression model which accounted for clustering at the household level and adjusted for all covariates included in Model 1 in Table 2, as well as for total degree.

${ }^{\star} P<0.05,{ }^{\star *} P<0.01,{ }^{* \star \star} P<0.001$.

$(b=0 \cdot 20,95 \%$ CI $0 \cdot 02,0 \cdot 37, P=0 \cdot 03)$, which was more than twice the size of the overall estimate in magnitude.

In addition, a statistically significant interaction effect was also estimated in Model 2 between food insecurity and the poverty composition of men's personal networks (e.g. quintiles of percentage poor; $F=2 \cdot 71, P=0 \cdot 047$ ). Thus, when stratifying Model 2 by network poverty composition, among men with few (0-20\%) poor contacts in their personal network, severe food insecurity had a statistically significant association with depression symptom severity ( $b=0.42,95 \%$ CI $0 \cdot 28,0 \cdot 57, P<0.001)$.
This estimate was about one-third more in magnitude than the overall estimate of the relationship between severe food insecurity and depression symptom severity for men. In contrast, among men with $40 \%$ or more poor contacts in their network, severe food insecurity had a smaller statistically significant association with depression symptom severity $(b=0 \cdot 19,95 \%$ CI $0 \cdot 04,0 \cdot 35)$, which was about one-third less in magnitude than the overall estimate. No other social network variables exhibited interaction effects or main effect associations for men. 


\section{Discussion}

More than two-thirds of adults in the current rural, population-based study in Uganda reported some level of food insecurity. The study demonstrates that within a general population of adults in a rural setting in Uganda, severe food insecurity (and to some extent moderate food insecurity) was a primary predictor of depression symptom severity for both men and women. These results are similar to findings from population-based studies in New Zealand, the USA and Canada ${ }^{(10,29,72)}$, and to a nationally representative study on US adults who fell $130 \%$ below the federal poverty level ${ }^{(73)}$. The relationship between food insecurity and depression symptom severity for both men and women in the present study remained robust after accounting for other factors including socioeconomic status and social network characteristics. Therefore, the potential for food insecurity to lead to significant mental health consequences among the general population in Uganda is of critical public health concern.

In addition, the study found novel evidence that, for men, two social network characteristics (i.e. social centrality in one's village network and the percentage of contacts in one's personal network who are poor) may moderate the way their perceived household food insecurity is related to their depression symptoms severity. In contrast, social networks did not seem to matter in the food insecurity and depression dynamic for women. These results differ from a study finding that instrumental social support moderated the association between food insecurity and depression symptom severity for women on antiretroviral therapy in Uganda, but not for men ${ }^{(21)}$. The new results also differ from another study finding that instrumental social support moderated the relationship between food insufficiency and depression symptom severity among pregnant women in peri-urban South Africa ${ }^{(23)}$. It is possible that severe food insecurity is experienced so regularly or profoundly by most women in rural Uganda that they typically experience less shame and stigma compared with men who may not experience severe food insecurity in such a persistent or profound way. Therefore, the mechanisms linking food insecurity and depression may differ, in part, between women in general and men in general in rural Uganda. For example, perhaps the link between food insecurity and depression has a greater biological and/or generalized stress basis for woman and a more social basis for men. If so, then social network factors could be less likely to affect the food insecurity-depression relationship for Ugandan women and more so for men. (Separately, the mechanisms linking food insecurity and depression may also differ between the general population of adults and specific marginalized populations given results from prior work.)

Future studies should explore whether perceived food insecurity-related stigma and shame could be possible mechanisms through which social networks moderate the role of food insecurity on men's mental health. Perhaps an inability to provide food for oneself or family is (perceived to be) judged very harshly by peers for men in patriarchal settings ${ }^{(74-76)}$ and thus it leads to feelings of shame. If so, then perhaps severely food-insecure men in the centre of their village social network would feel even more embarrassed and stressed about their situation (due to the greater possibility that more people would find out about their severe food insecurity) than would severely foodinsecure men on the periphery of their village social network. This additional stress may turn into increased depression symptom severity for these food-insecure men who are highly embedded within their village social network. Similarly, men may make assumptions about whether their contacts are experiencing food insecurity based on their contacts' visible assets, which may not be a good indicator if men tend to hide food insecurity. If foodinsecure men with few poor contacts assume a significant proportion of their network to either not experience food insecurity and/or not understand their situation, then such assumptions could create a heightened sense of 'otherness' and shame, and ultimately lead to greater depression symptoms as compared with food-insecure men with many poor contacts who may not feel like an outsider or as judged.

Although future research is needed to test those hypotheses, the lack of moderation on the food insecuritydepression dynamic by the prevalence of moderate to severe food insecurity among men's personal networks supports this theory about the potential role of food-related stigma. If men generally try to hide their food insecurity status, then men may not be aware of others' food insecurity in the same way they are aware of others' tangible assets. Thus, feeling the need to hide one's food insecurity in the presence of wealthy people could increase shame and, therefore, depression symptoms, among severely food-insecure men with less poor networks, as well as reduce their likelihood to ask for help, as compared with severely food-insecure men with poor networks. Evidence from a study on men and women in rural Zambia of a negative relationship between relative deprivation and BMI would seem to support this idea of shame and men not wanting to reach out to others if they feel relatively worse off ${ }^{(77)}$

Taken together, these results suggest that food insecurity interventions may help alleviate depression symptoms (in addition to food insecurity) and that they might be more effective (and produce fewer unintended consequences) if they are designed with different populations in mind. For example, among the overall population of food-insecure women, general food insecurity interventions may reduce women's depression symptom severity (as well as food insecurity). The same interventions may be less effective, however, in addressing food insecurity and depression for severely food-insecure men and may be contingent on their social network context (e.g. the 
wealth of their personal network or their embeddedness within their community network). Yet, if the interventions targeting men are designed to reduce the potential for public embarrassment (and thus shame and stigma), then such interventions might be effective among all severely food-insecure men. Finally, the present study does not suggest that food insecurity interventions should be designed to manipulate social network factors, such as network composition. Rather, the present results suggest that the social network context should be taken into account when designing food insecurity interventions that target men. In-depth assessment of the direct relationship between social networks and food insecurity, or between social networks and depression, may be important areas for future study.

Interpretation of the study's findings is subject to several important limitations. First, we lacked data on the extent to which study participants met formal diagnostic criteria for major depressive disorder. Sub-syndromal symptoms are commonly experienced during the course of mood disorders, however, and are associated with significant psychosocial impairment ${ }^{(78,79)}$. In addition, our food insecurity measure did not differentiate between household food insecurity, child food insecurity and other specific aspects of nutritional insecurity. Future studies could validate the study's results by using another measure ${ }^{(80)}$. Second, we lacked data to adjust for any physical health outcomes and other potential confounders that may be linked to both food insecurity and depression symptoms. Third, the data are self-reported and therefore are subject to the challenges inherent to all studies based on self-reported data. Collecting objective data such as stress-related biomarkers, anthropometric data and micronutrient levels may help clarify the physical and psychosocial health-related consequences of food insecurity $^{(81)}$.

Finally, the cross-sectional design precludes our ability to make causal claims. It is possible that the direction of influence could run from depression symptom severity to food insecurity or in both directions as a longitudinal study of rural families in the USA found ${ }^{(82)}$. However, our findings are consistent with the results from four recent longitudinal studies that employed a fixed-effects study design (of which three were conducted with subpopulations in sub-Saharan Africa) ${ }^{(21,23,26,83)}$. Adjusting for unobserved time-invariant confounding, they found that food insecurity led to depression symptoms. In addition, a study from the USA recently demonstrated that participation in a nutrition assistance programme reduced psychological distress ${ }^{(84)}$, and a recent quasi-experimental study from Bangladesh found that food insecurity was the primary mediator between poverty and distress as well as having a direct effect ${ }^{(85)}$. Future research employing a study design to determine causal direction between food insecurity and mental health outcomes, and including measures of perceived food insecurity-related stigma, social support and overall time spent experiencing food insecurity, may uncover potential mechanisms linking social network characteristics, food insecurity and depression, particularly for men.

\section{Conclusions}

The current study provides clear evidence of a robust link between moderate to severe food insecurity and depression symptoms for both men and women in the general population in rural Uganda. This finding is particularly concerning given that the vast majority of people in Uganda live in rural areas and many rely on subsistence farming ${ }^{(86,87)}$, that Uganda is one of the few countries where the proportion of undernourished people actually increased from 1990-92 to 2012-14 ${ }^{(1)}$, that the majority of adults in the present study reported some level of food insecurity, and that depression is a leading cause of disability $^{(88)}$. Thus, population-wide nutrition interventions aimed at improving food insecurity in Uganda might actually address at least two major health and development issues for the general population. Future research is needed, however, to elucidate the role of social network composition on the food insecurity-mental health dynamic for men and why evidence of effect modification does not appear for women. The effectiveness of food insecurity interventions might be greater if men's social context and social interpretation of food insecurity were acknowledged in the design of such interventions and opportunities for public embarrassment reduced.

\section{Acknowledgements}

Acknowledgements: The authors thank the Emikago Study team members for their assistance with data collection and study administration; and Niels Rosenquist, Sae Takada, Peggy Bartek, Anna Baylor, Pamela Mbabazi, Nozmo F.B. Mukiibi and Roberts Muriisa for their assistance with study administration and infrastructure development. Financial support: This study was supported by Friends of a Healthy Uganda and by a Roybal Center grant through the US National Institutes of Health (NIH; grant number P30AG034420). The authors also acknowledge salary support from the NIH (grant number K23MH096620). The funders had no role in the design, analysis or writing of this article. Conflicts of interest: None. Authorship: J.M.P. conceived of and designed the study. J.M.P., V.N.N. and B.K. participated in the data collection. J.M.P. wrote the first draft. J.M.P., V.N.N., B.K., A.C.T., S.V.S., D.R.B. and N.A.C. provided critical revisions. A.C.T., D.R.B. and N.A.C. provided study oversight. Ethics of human subject participation: This study was conducted according to the guidelines laid down in the Declaration of Helsinki and all procedures involving human subjects/patients were 
approved by the Committee on the Use of Human Subjects in Research, Harvard University; the Partners Human Research Committee, Massachusetts General Hospital; and the Institutional Review Committee, Mbarara University of Science and Technology. We also received clearance for the study from the Uganda National Council for Science and Technology and from the Research Secretariat in the Office of the President. Written informed consent was obtained from all subjects/patients.

\section{References}

1. Food and Agriculture Organization of the United Nations, International Fund for Agricultural Development \& World Food Programme (2014) The State of Food Insecurity in the World 2014: Strengthening the Enabling Environment for Food Security and Nutrition. Rome: FAO.

2. United Nations (2016) Sustainable Development Goals: 17 Goals to Sustain Our World. http://www.un.org/sustaina bledevelopment/hunger/ (accessed June 2016).

3. Anderson S (1990) Core indicators of nutritional state for difficult-to-sample populations. J Nutr 120, 1555-1600.

4. Stuff JE, Casey PH, Szeto KL et al. (2004) Household food insecurity is associated with adult health status. J Nutr 134, 2330-2335.

5. Siefert K, Heflin CM, Corcoran ME et al. (2001) Food insufficiency and the physical and mental health of lowincome women. Women Health 32, 159-177.

6. Lee JS \& Frongillo EA (2001) Nutritional and health consequences are associated with food insecurity among US elderly persons. J Nutr 131, 1503-1509.

7. Vozoris NT \& Tarasuk VS (2003) Household food insufficiency is associated with poorer health. J Nutr 133, 120-126.

8. Seligman HK, Laraia BA \& Kushel MB (2010) Food insecurity is associated with chronic disease among low-income NHANES participants. J Nutr 140, 304-310.

9. Hadley C \& Crooks DL (2012) Coping and the biosocial consequences of food insecurity in the 21st century. $A m \mathrm{~J}$ Phys Anthropol 149, 72-94.

10. Carter KN, Kruse K, Blakely T et al. (2011) The association of food security with psychological distress in New Zealand and any gender differences. Soc Sci Med 72, 1463-1471.

11. Friel S, Berry H, Dinh H et al. (2014) The impact of drought on the association between food security and mental health in a nationally representative Australian sample. $B M C$ Public Health 14, 1102.

12. Heflin CM, Siefert K \& Williams DR (2005) Food insufficiency and women's mental health: findings from a 3-year panel of welfare recipients. Soc Sci Med 61, 1971-1982.

13. Weaver LJ \& Hadley C (2009) Moving beyond hunger and nutrition: a systematic review of the evidence linking food insecurity and mental health in developing countries. Ecol Food Nutr 48, 263-284.

14. Davison KM, Marshall-Fabien GL \& Tecson A (2015) Association of moderate and severe food insecurity with suicidal ideation in adults: national survey data from three Canadian provinces. Soc Psychiatry Psychiatr Epidemiol 50, 963-972.

15. Muldoon KA, Duff PK, Fielden S et al. (2012) Food insufficiency is associated with psychiatric morbidity in a nationally representative study of mental illness among food insecure Canadians. Soc Psychiatry Psychiatr Epidemiol 48, 795-803.

16. Hadley C, Galea S, Nandi V et al. (2008) Hunger and health among undocumented Mexican migrants in a US urban area. Public Health Nutr 11, 151-158.
17. Moraes CLd, Marques ES, Reichenheim ME et al. (2016) Intimate partner violence, common mental disorders and household food insecurity: an analysis using path analysis. Public Health Nutr 19, 2965-2974.

18. Hadley C \& Patil CL (2008) Seasonal changes in household food insecurity and symptoms of anxiety and depression. Am J Phys Anthropol 135, 225-232.

19. Hadley C, Tegegn A, Tessema F et al. (2008) Food insecurity, stressful life events and symptoms of anxiety and depression in East Africa: evidence from the Gilgel Gibe Growth and Development Study. J Epidemiol Community Health 62, 980-986.

20. Hadley C \& Patil CL (2006) Food insecurity in rural Tanzania is associated with maternal anxiety and depression. $A m \mathrm{~J}$ Hum Biol 18, 359-368.

21. Tsai AC, Bangsberg DR, Frongillo EA et al. (2012) Food insecurity, depression and the modifying role of social support among people living with HIV/AIDS in rural Uganda. Soc Sci Med 74, 2012-2019.

22. Dewing S, Tomlinson M, le Roux IM et al. (2013) Food insecurity and its association with co-occurring postnatal depression, hazardous drinking, and suicidality among women in peri-urban South Africa. J Affect Disord 150, 460-465.

23. Tsai AC, Tomlinson M, Comulada Ws et al. (2016) Food insufficiency, depression, and the modifying role of social support: evidence from a population-based, prospective cohort of pregnant women in peri-urban South Africa. Soc Sci Med 151, 69-77.

24. Maharaj V, Tomita A, Thela L et al. (2016) Food Insecurity and risk of depression among refugees and immigrants in South Africa. J Immigr Minor Health 19, 631-637.

25. Maes KC, Hadley C, Tesfaye F et al. (2010) Food insecurity and mental health: surprising trends among community health volunteers in Addis Ababa, Ethiopia during the 2008 food crisis. Soc Sci Med 70, 1450-1457.

26. Cole SM \& Tembo G (2011) The effect of food insecurity on mental health: panel evidence from rural Zambia. Soc Sci Med 73, 1071-1079.

27. Quisumbing AR, Brown L, Feldstein $\mathrm{H}$ et al. (1995) Women: The Key to Food Security. Washington, DC: International Food Policy Research Institute.

28. Gupta R, Dandu M, Packel L et al. (2010) Depression and HIV in Botswana: a population-based study on genderspecific socioeconomic and behavioral correlates. PLoS One $\mathbf{5}, \mathrm{e} 1452$.

29. Wu Z \& Schimmele CM (2005) Food Insufficiency and depression. Sociol Perspect 48, 481-504.

30. Misselhorn AA (2005) What drives food insecurity in southern Africa? A meta-analysis of household economy studies. Glob Environ Chang 15, 33-43.

31. Oldewage-Theron WH, Dicks EG \& Napier CE (2006) Poverty, household food insecurity and nutrition: coping strategies in an informal settlement in the Vaal Triangle, South Africa. Public Health 120, 795-804.

32. Smith LC, El Obeid AE \& Jensen HH (2000) The geography and causes of food insecurity in developing countries. Agric Econ 22, 199-215.

33. De Cock N, D'Haese M, Vink N et al. (2013) Food security in rural areas of Limpopo province, South Africa. Food Secur $\mathbf{5}$, 269-282.

34. Kinyanda E, Woodburn P, Tugumisirize J et al. (2011) Poverty, life events and the risk for depression in Uganda. Soc Psychiatry Psychiatr Epidemiol 46, 35-44.

35. Lund C, Breen A, Flisher AJ et al. (2010) Poverty and common mental disorders in low and middle income countries: a systematic review. Soc Sci Med 71, 517-528.

36. Cobb S (1976) Social support as a moderator of life stress. Psychosom Med 38, 300-314. 
37. Cohen S \& McKay G (1984) Social support, stress and the buffering hypothesis: a theoretical analysis. In Handbook of Psychology and Health, pp. 253-267 [A Baum, SE Taylor and JE Singer, editors]. Hillsdale, NJ: Erlbaum.

38. Cohen S \& Wills TA (1985) Stress, social support, and the buffering hypothesis. Psychol Bull 98, 310-357.

39. Kollannoor-Samuel G, Wagner J, Damio G et al. (2011) Social support modifies the association between household food insecurity and depression among Latinos with uncontrolled type 2 diabetes. I Immigr Minor Health $\mathbf{1 3}$ 982-989.

40. Natamba B, Mehta S, Mou S et al. (2015) Social support modifies bidirectional linkages between food insecurity and prenatal depressive symptoms while domestic violence alters the unidirectional impact of food insecurity on prenatal depressive symptoms. FASEB J 29, Suppl. 1, 261.8.

41. Kapulsky L, Tang A \& Forrester J (2015) Food insecurity, depression, and social support in HIV-infected Hispanic individuals. J Immigr Minor Health 17, 408-413.

42. Berkman LF, Glass T, Brissette I et al. (2000) From social integration to health: Durkheim in the new millennium. Soc Sci Med 51, 843-857.

43. Tsai AC \& Papachristos AV (2015) From social networks to health: Durkheim after the turn of the millennium. $S o c S c i$ Med 125, 1-7.

44. Nanama S \& Frongillo EA (2012) Altered social cohesion and adverse psychological experiences with chronic food insecurity in the non-market economy and complex households of Burkina Faso. Soc Sci Med 74, 444-451.

45. Oliva GS, de Mendonca RG, Sant'Anna MJ et al. (2008) Integral care for pregnant adolescents: impact on offspring. Int J Adolesc Med Health 20, 537-546.

46. Hadley C, Lindstrom D, Tessema F et al. (2008) Gender bias in the food insecurity experience of Ethiopian adolescents. Soc Sci Med 66, 427-438.

47. Berkman LF \& Syme SL (1979) Social networks, host resistance, and mortality: a nine year follow up of Alameda County residents. Am J Epidemiol 109, 186-204.

48. Tsai AC, Bangsberg DR, Emenyonu N et al. (2011) The social context of food insecurity among persons living with HIV/AIDS in rural Uganda. Soc Sci Med 73, 1717-1724.

49. Tsai AC, Kakuhikire B, Mushavi R et al. (2016) Populationbased study of intra-household gender differences in water insecurity: reliability and validity of a survey instrument for use in rural Uganda. J Water Health 14, 280-292.

50. Tuller DM, Bangsberg DR, Senkungu J et al. (2010) Transportation costs impede sustained adherence and access to HAART in a clinic population in southwestern Uganda: a qualitative study. AIDS Behav 14, 778-784.

51. Siedner MJ, Lankowski A, Tsai AC et al. (2013) GPSmeasured distance to clinic, but not self-reported transportation factors, are associated with missed HIV clinic visits in rural Uganda. AIDS 27, 1503-1508.

52. Tsai AC, Kakuhikire B, Perkins JM et al. (2017) Measuring personal beliefs and perceived norms about intimate partner violence: population-based survey experiment in rural Uganda. PLOS Med 14, e1002303.

53. World Bank (2016) The Uganda Poverty Assessment Report 2016. Washington, DC: The World Bank Group.

54. Derogatis LR, Lipman RS, Rickels K et al. (1974) The Hopkins Symptom Checklist (HSCL): a self-report symptom inventory. Behav Sci 19, 1-15.

55. Bolton P \& Ndogoni L (2001) Cross-Cultural Assessment of Trauma-Related Mental Illness (Phase II): A Report of Research Conducted by World Vision Uganda and the Johns Hopkins University. Baltimore, MD: Johns Hopkins University.

56. Martinez P, Andia I, Emenyonu N et al. (2008) Alcohol use, depressive symptoms and the receipt of antiretroviral therapy in southwest Uganda. AIDS Behav 12, 605-612.
57. Ashaba S, Kakuhikire B, Vorechovska D et al. (2017) Reliability, validity, and factor structure of the Hopkins Symptom Checklist-25: population-based study of persons living with HIV in rural Uganda. AIDS Behav (Epublication ahead of print version).

58. Winokur A, Winokur DF, Rickels $\mathrm{K}$ et al. (1984) Symptoms of emotional distress in a family planning service: stability over a four-week period. Br J Psychiatry 144, 395-399.

59. Coates J, Swindale A \& Bilinsky P (2006) Household Food Insecurity Access Scale (HFIAS) for Measurement of Food Access: Indicator Guide. Washington, DC: Academy for Educational Development.

60. Burt RS (1984) Network items and the general social survey. Soc Network 6, 293-339.

61. Perkins JM, Subramanian SV \& Christakis NA (2015) Social networks and health: a systematic review of sociocentric network studies in low- and middle-income countries. Soc Sci Med 125, 60-78.

62. Marin A \& Hampton KN (2007) Simplifying the personal network name generator: alternatives to traditional multiple and single name generators. Field Method 19, 163-193.

63. Wasserman S \& Faust K (1994) Social Network Analysis: Methods and Applications. Cambridge: Cambridge University Press.

64. Sabidussi G (1966) The centrality index of a graph. Psychometrika 31, 581-603.

65. Filmer D \& Pritchett LH (2001) Estimating wealth effects without expenditure data - or tears: an application to educational enrollments in states of India. Demography 38, 115-132.

66. Patterson K, Berrang-Ford L, Lwasa S et al. (2017) Seasonal variation of food security among the Batwa of Kanungu, Uganda. Public Health Nutr 20, 1-11.

67. Mayanja MN, Rubaire-Akiiki C, Greiner T et al. (2015) Characterising food insecurity in pastoral and agro-pastoral communities in Uganda using a consumption coping strategy index. Pastoralism 5, 11.

68. Haile M (2005) Weather patterns, food security and humanitarian response in sub-Saharan Africa. Philos Trans $R$ Soc B Biol Sci 360, 2169-2182.

69. Anema A, Vogenthaler N, Frongillo E et al. (2009) Food insecurity and HIV/AIDS: current knowledge, gaps, and research priorities. Curr HIV/AIDS Rep 6, 224-231.

70. Ciesla JA \& Roberts JE (2001) Meta-analysis of the relationship between HIV infection and risk for depressive disorders. Am J Psychiatry 158, 725-730.

71. Whitaker RC, Phillips SM \& Orzol SM (2006) Food insecurity and the risks of depression and anxiety in mothers and behavior problems in their preschool-aged children. Pediatrics 118, e859-e868.

72. Okechukwu CA, El Ayadi AM, Tamers SL et al. (2012) Household food insufficiency, financial strain, work-family spillover, and depressive symptoms in the working class: the Work, Family, and Health Network study. Am J Public Health 102, 126-133.

73. Leung CW, Epel ES, Willett WC et al. (2015) Household food insecurity is positively associated with depression among low-income Supplemental Nutrition Assistance Program participants and income-eligible nonparticipants. $J$ Nutr 145, 622-627.

74. Silberschmidt M (2005) Poverty, male disempowerment, and male sexuality: rethinking men and masculinities in rural and urban East Africa. In African Masculinities: Men in Africa from the Late Nineteenth Century to the Present, pp. 189-203 [L Ouzgane and R Morrell, editors]. New York: Palgrave Macmillan US.

75. Silberschmidt M (2001) Disempowerment of men in rural and urban East Africa: implications for male identity and sexual behavior. World Dev 29, 657-671. 
76. Wilson F (2006) On being a father and poor in southern Africa today. In Baba: Men and Fatherhood in South Africa, pp. 26-37 [L Richter and R Morrell, editors]. Cape Town: Human Sciences Research Council.

77. Cole SM (2012) The relationship between relative deprivation and adult nutritional status in rural Zambia. Am J Hum Biol 24, 800-805.

78. Judd LL, Akiskal HS, Maser JD et al. (1998) A prospective 12-year study of subsyndromal and syndromal depressive symptoms in unipolar major depressive disorders. Arch Gen Psychiatry 55, 694-700.

79. Judd LL, Akiskal HS, Zeller PJ et al. (2000) Psychosocial disability during the long-term course of unipolar major depressive disorder. Arch Gen Psychiatry 57, 375-380.

80. Leyna GH, Mmbaga EJ, Mnyika KS et al. (2008) Validation of the Radimer/Cornell food insecurity measure in rural Kilimanjaro, Tanzania. Public Health Nutr 11, 684-689.

81. Pike IL \& Williams SR (2006) Incorporating psychosocial health into biocultural models: preliminary findings from Turkana women of Kenya. Am J Hum Biol 18, 729-740.

82. Huddleston-Casas C, Charnigo R \& Simmons LA (2009) Food insecurity and maternal depression in rural, low-income families: a longitudinal investigation. Public Health Nutr 12, 1133-1140.

83. Palar K, Kushel M, Frongillo E et al. (2015) Food insecurity is longitudinally associated with depressive symptoms among homeless and marginally-housed individuals living with HIV. AIDS Behav 19, 1527-1534.

84. Oddo VM \& Mabli J (2015) Association of participation in the Supplemental Nutrition Assistance Program and psychological distress. Am J Public Health 105, e30-e35.

85. Jalal CS, Frongillo EA \& Warren AM (2015) Food insecurity mediates the effect of a poverty-alleviation program on psychosocial health among the ultra-poor in Bangladesh. J Nutr 145, 1934-1941.

86. Ugandan Bureau of Statistics \& ICF International (2011) Uganda Demographic and Health Survey 2011. http://www. ubos.org/onlinefiles/uploads/ubos/UDHS/UDHS2011.pdf (accessed March 2015).

87. World Bank (2015) Uganda. http://data.worldbank.org/ country/uganda (accessed March 2015).

88. Marcus M, Taghi Yasamy T, van Ommeren M et al. (2012) Depression: A Global Public Health Concern. Geneva: WHO. 